\title{
MATHEMATICS TEACHERS' KNOWLEDGE FOR TEACHING PROBLEM SOLVING
}

\author{
Olive Chapman \\ University of Calgary • chapman@ucalgary.ca
}

\begin{abstract}
In recent years, considerable attention has been given to the knowledge teachers ought to hold for teaching mathematics. Teachers need to hold knowledge of mathematical problem solving for themselves as problem solvers and to help students to become better problem solvers. Thus, a teacher's knowledge of and for teaching problem solving must be broader than general ability in problem solving. In this article a category-based perspective is used to discuss the types of knowledge that should be included in mathematical problem-solving knowledge for teaching. In particular, what do teachers need to know to teach for problem-solving proficiency? This question is addressed based on a review of the research literature on problem solving in mathematics education. The article discusses the perspective of problem-solving proficiency that framed the review and the findings regarding six categories of knowledge that teachers ought to hold to support students' development of problem-solving proficiency. It concludes that mathematics problem-solving knowledge for teaching is a complex network of interdependent knowledge. Understanding this interdependence is important to help teachers to hold mathematical problem-solving knowledge for teaching so that it is usable in a meaningful and effective way in supporting problem-solving proficiency in their teaching. The perspective of mathematical problem-solving knowledge for teaching presented in this article can be built on to provide a framework of key knowledge mathematics teachers ought to hold to inform practice-based investigation of it and the design and investigation of learning experiences to help teachers to understand and develop the mathematics knowledge they need to teach for problemsolving proficiency.
\end{abstract}

\section{Introduction}

In recent years, considerable attention has been given to the knowledge teachers ought to hold for teaching mathematics. While there are various perspectives in which to interpret the nature of this knowledge (e.g. Rowland \& Ruthven, 2011), categories of knowledge such as proposed by Ball, Thames, and Phelps (2008) have received significant attention in mathematics teacher education as a basis of gaining insights of this knowledge. While this category-based perspective does not provide a complete picture of the knowledge, it enables us to consider important aspects of the knowledge. In this article a category-based perspective is being used to discuss the mathematical problem-solving knowledge teachers ought to hold.

Ball, Thames, and Phelps (2008) suggested that general mathematical ability does not fully account for the knowledge and skills needed for effective mathematics teaching. Teachers need a special type of knowledge that is not needed in other professional settings. For example, the conceptual demands of teaching mathematics are different than the mathematical under-standings needed by mathematicians. Similarly, the knowledge needed to effectively teach problem solving should be more than general problem-solving ability. 
Thus the goal here is to address the following questions: What types of knowledge ought to be included in mathematical problem-solving knowledge for teaching (MPSKT)? In particular, what do teachers need to know to teach for problem-solving proficiency? These questions are discussed based on a review of research literature on problem solving in mathematics education.

Research on mathematical problem solving [PS] has a long history dealing with fundamental questions regarding the teaching and learning of PS. While the focus has been more on the learner in the early years and on the teacher in recent years, this body of studies directly or indirectly offers suggestions of the knowledge teachers ought to hold to teach PS. However, the goal here is not an exhaustive review of this large body of literature, but to consider a sample of studies that suggests different categories of this knowledge to teach for PS proficiency.

The review began with current literature involving "problem solving" and evolved into considering much earlier studies of "problem solving" resulting in a sample of studies from 1922 to 2013. This sample was obtained by a search of articles on PS in international mathematics education journals and books involving theory/research on PS in mathematics education. After compiling the list of references, based on titles and abstracts they were sorted into categories that suggest different types of knowledge that were important for teaching PS. With the aid of research assistants, these categories were validated, revised and extended after reading, highlighting and summarizing relevant information of the articles/chapters for each category. Some sources covered several of the categories. The information collected for each category was further reviewed to identify what directly or indirectly suggested knowledge of importance to teach for problem-solving proficiency. This article discusses the perspective of PS proficiency considered in the review and the findings regarding six categories of knowledge that teachers ought to hold to support students' development of PS proficiency.

\section{Mathematical problem-solving proficiency}

Theoretically, genuine PS involves "engaging in a task for which the solution method is not known in advance" (National Council of Teachers of Mathematics, 2000, p. 52); "finding a way out of a difficulty, a way around an obstacle, attaining an aim which was not immediately attainable" (Polya, 1962, p. v). It is "a form of cognitive processing you engage in when faced with a problem and do not have an obvious method of solution" (Mayer \& Wittrock, 2006, p. 287). MPSKT is being based on this perspective of PS with a focus on PS proficiency.

Problem-solving proficiency is used here to represent what is necessary for one to learn and do genuine PS successfully. This is similar to Kilpatrick, Swafford, and Findell's (2001) use of mathematical proficiency. As they explained: "we have chosen mathematical proficiency to capture what we believe is necessary for anyone to learn mathematics successfully" (p. 116). Thus PS proficiency is defined based on characteristics suggested for 
successful PS and their relationship to mathematical proficiency given the direct relationship between the two. As Kilpatrick et al. noted, "We believe problem solving is vital because it calls on all strands of [mathematical] proficiencies" (p. 421).

For successful PS, according to Schoenfeld (1985), one must be equipped with and competently use appropriate resources (e.g. mathematics concepts and procedures), heuristic strategies (specific and general heuristics), metacognitive control (monitoring and overseeing the entire PS process), and appropriate beliefs (one's perspective, motivation, and confidence). Similarly, according to Mayer and Wittrock (2006), students need five kinds of knowledge in order to be successful problem solvers: facts (knowledge about characteristics of elements, e.g. $100 \mathrm{~cm}$ in a meter), concepts (knowledge of categories, principles, or models, e.g. what place value means), strategies (knowledge of general methods), procedures (knowledge of specific procedures), beliefs (cognitions about one's PS competence or about the nature of PS), meta-cognitive knowledge (awareness and control of one's own cognitive processing and includes beliefs).

For mathematical proficiency, Kilpatrick et al. (2001) identified five components in defining it: conceptual understanding (comprehension of mathematical concepts, operations, and relations); procedural fluency (skill in carrying out procedures flexibly, accurately, efficiently, and appropriately); strategic competence (ability to formulate, represent, and solve mathematical problems); adaptive reasoning (capacity for logical thought, reflection, explanation, and justification); and productive disposition (habitual inclination to see mathematics as sensible, useful, worthwhile, coupled with a belief in diligence and one's own efficacy).

Based on these components for successful PS and mathematical proficiency, Table 1 shows a possible relationship between them that provide a perspective of PS proficiency in teaching mathematics. In this relationship, conceptual understanding and procedural fluency embody the type of knowledge and skills that are the resources required for effective PS; strategic competence involves ability to formulate, represent, and solve mathematical problems; productive disposition includes beliefs; and adaptive reasoning includes capacity of logical thought and reflection.

This relationship between PS and mathematical proficiency has important implications for teaching and learning PS in the mathematics classroom. As Kilpatrick et al. (2001) noted,

The components of mathematical proficiency are not independent, they represent different aspects of a complex whole. (...) [They are] interwoven and interdependent in the development of proficiency in mathematics. ... Mathematical proficiency is not a one dimensional trait, and it cannot be achieved by focusing on just one or two of these strands. ... Helping children acquire mathematical proficiency calls for instructional programs that address all its strands. (p. 116) 
Table 1 Perspective of mathematical PS proficiency

\begin{tabular}{|c|c|c|c|}
\hline $\begin{array}{l}\text { Mayer \& Wittrock } \\
(2006)\end{array}$ & $\begin{array}{l}\text { Schoenfeld } \\
(1985)\end{array}$ & $\begin{array}{l}\text { Kilpatrick et al, } \\
2001\end{array}$ & Mathematical PS proficiency \\
\hline $\begin{array}{l}\text { Concepts } \\
\text { Procedures }\end{array}$ & $\begin{array}{l}\text { Appropriate } \\
\text { Resources }\end{array}$ & $\begin{array}{l}\text { Conceptual understanding and } \\
\text { procedural fluency }\end{array}$ & $\begin{array}{l}\text { Conceptual understanding of } \\
\text { mathematical concepts, operations, and } \\
\text { relations }\end{array}$ \\
\hline Strategies & $\begin{array}{l}\text { Heuristic } \\
\text { Strategies }\end{array}$ & Strategic competence & $\begin{array}{l}\text { Understanding of general heuristics } \\
\text { and specific strategies and when and } \\
\text { how to use them }\end{array}$ \\
\hline $\begin{array}{l}\text { Metacognitive } \\
\text { knowledge }\end{array}$ & $\begin{array}{l}\text { Metacognitive } \\
\text { control }\end{array}$ & Adaptive reasoning & $\begin{array}{l}\text { Capacity for logical thought and } \\
\text { understanding of reflection for } \\
\text { awareness, monitoring, controlling and } \\
\text { overseeing one's own cognitive } \\
\text { processing during PS }\end{array}$ \\
\hline Beliefs & $\begin{array}{l}\text { Appropriate } \\
\text { beliefs }\end{array}$ & Productive disposition & $\begin{array}{l}\text { Holding beliefs about mathematics, PS } \\
\text { and one's PS competence that support } \\
\text { motivation and confidence }\end{array}$ \\
\hline
\end{tabular}

Thus, like mathematical proficiency, PS proficiency is not a one-dimensional concept and cannot be achieved by focusing on just one or two of the factors that define it. Helping children to develop PS proficiency will require instructional practices that address all of the factors in Table 1 in an interrelated way. In order to accomplish this, teachers will have to know not only how to solve problems but hold a deep understanding of other factors that are associated with the development of proficiency in PS. These factors are discussed next as six key components of MPSKT.

\section{Knowledge of problems}

Teachers need to be proficient in selecting and designing mathematical problems to support students' PS proficiency, which requires an understanding of the nature of problems. Chapman (2009a) found that teachers could hold different conceptions of contextual problems that have the potential to limit or enhance how PS is perceived, experienced, and learnt by their students. However, MPSKT should include a view of problems as mathematical tasks for which the student does not have an obvious way to solve it. Charles and Lester (1982) offered the following definition "[to provide] teachers with some guidelines for deciding whether a task really is a problem for students" (p. 5).

A problem is a task for which:

1. The person confronting it wants or needs to find a solution.

2. The person has no readily available procedure for finding the solution.

3. The person must make an attempt to find a solution. (p. 5) 
Teachers should also understand problems based on their structure and purpose in order to make sense of how to guide students' solutions. As Polya (1962) noted, useful questions to ask when one encounters a problem are: "What kind of problem is this?" and "What can be done about this kind of problem?” (p. 118). He explained:

The aim is to familiarize you with the principal parts of problems. But if seriously asked and carefully answered, they are a great help in problem solving: in focusing your attention upon the principal parts of the problem, they deepen your understanding of the problem and they may start you in the right direction. (p. 118)

Other aspects of structure or characteristics of problems that could impact students' PS include:

the problem statement (e.g., the complexity of the syntax, the semantics or linguistic content, [the context], the amount of information given) ... the mode of presentation ... the mathematical structure of the problem (e.g., the number of steps and operations involved, the number of conditions and variables) and the heuristic processes that might be particularly useful in reaching a solution. (Silver \& Thompson, 1984, p. 531)

Studies investigating such characteristics suggest knowledge teachers should hold about them and possible impact on students' learning of PS, for example, as in Table 2.

Table 2 Impact of problem characteristics on students' PS

Students have much more difficulty with multistep problems Silver \& Thompson, 1984 than with one-step problems and problems in which the action is explicit in the problem statement are easier than problems in which the action is implied

The semantic structure of word problems directly influences the number sentences that young children write to represent them

For secondary students, concrete problems were significantly less difficult than abstract problems while factual problems were less difficult than hypothetical problems

Problem structure had a strong effect on children's solution strategies

The telegraphic format, with its bare-bone syntax, did not facilitate students' performance on story problems.

Students often experience difficulties in understanding the text of a word problem rather than its solution

Students' ability to solve word problems is affected by the method of presentation and the presentation of accurate pictures aids student achievement with word problems while the presentation of inaccurate pictures hinders their solutions
Carpenter, Fennema, Peterson \& Carey, 1988

Caldwell \& Goldin, 1987
De Corte \& Verschaffel, 1987

Moyer, Moyer, Sowder, \&

Threadgill-Sowder, 1984

Lewis \& Mayer, 1987

Webb \& Sherrill, 1974 
Recent studies that helped teachers to enhance their knowledge of meaningful problems also suggest different types of problems that are important for teachers to know for teaching PS. For example, studies have engaged teachers in posing and evaluating problems (Crespo \& Sinclair, 2008; Lee, 2012); posing cognitively demanding tasks (Norton \& Kastberg, 2012); multiple-solution tasks (Guberman \& Leikin, 2013); tasks with potential to occasion/promote mathematical creativity in problem solving (Levenson, 2013); demanding problems that generally allowed for a variety of problem-solving strategies (Szydlik, Szydlik, \& Benson, 2003); rich mathematical tasks (Slavit \& Nelson, 2010); metamathematical awareness of the interest and difficulty of any given problem (Leiken, 2003); and understanding levels of cognitive demand of problems (Arbaugh \& Brown, 2004). These studies suggest that teachers need to have knowledge of a variety of problems that are relevant for teaching for PS proficiency. In particular, they should understand the nature of open-ended problems. In Chapman (2012), the prospective elementary teachers' common thinking was that open-ended meant more than one answer but there was uncertainty about what this meant mathematically. One participant explained, "Openended means more than one answer, but when I think of math I can only think of one answer, so I couldn't provide an example” (p.141). Mason et al (2010) provides examples of open-ended problems for teachers' learning that will support their MPSKT.

\section{$4 \quad$ Knowledge of problem solving}

MPSKT should obviously include knowledge of PS. Thus, to teach for PS proficiency, teachers should be proficient in PS and understand the nature of it in order to teach it effectively. As Thompson (1985) explained,

I noticed that Jeanne [her participant] had skipped some pages in the textbook containing story problems involving rates and proportions. ... she then indicated that the reason for her skipping the pages involving problems was that the students did not enjoy working them and that problems caused them to experience a great deal of frustration with mathematics. (p. 288)

This experience made her argue for teachers "to experience mathematical problem solving from the perspective of the problem solver before they can adequately deal with its teaching" (p. 292).

Other concerns are reflected in studies regarding teachers' proficiency in PS. Table 3 provides examples of these studies and findings involving prospective mathematics teachers.

These studies not only create awareness of limitations of teachers' knowledge of PS for teaching, but also imply the nature of the knowledge needed to establish their proficiency in PS. Other studies have focused on helping prospective teachers to develop this proficiency by engaging them in activities that include individual and group PS (e.g. Chapman, 2009b; Szydlik, Szydlik, \& Benson, 2003). Teachers' proficiency in PS is important for them to be able to interpret students' unusual solutions, understand implications of students' different 
Table 3 Concerns regarding prospective teachers' proficiency in PS

\begin{tabular}{|c|c|}
\hline $\begin{array}{l}\text { Inability to successfully relate their solutions to } \\
\text { real life, PS contexts }\end{array}$ & $\begin{array}{l}\text { Tirosh \& Graeber, 1989; Tirosh, Tirosh, } \\
\text { Graeber, \& Wilson, } 1991\end{array}$ \\
\hline Lack of flexibility in choice of PS approaches & van Dooren, Verschaffel, \& Onghena, 2003 \\
\hline $\begin{array}{l}\text { Preference to work with a narrow range of } \\
\text { strategies and selected a method and not change } \\
\text { from that even if not productive, implying } \\
\text { inflexibility in their choice or management of PS } \\
\text { strategies }\end{array}$ & Chapman, 1999; Taplin, 1994 \\
\hline
\end{tabular}

Tendency to apply a stereotypical solution to a Leikin, 2003

problem, e.g. connected a particular

mathematical topic to a particular PS strategy

Understanding of PS as a linear process involving Chapman, 2005

solving algorithmic word problems

A lack of strategies for interpreting the

Taplin, 1998

information given to them in word problems and

to recognise the appropriate procedure to use

approaches, whether they may be fruitful and, if not, what might make them so; and make connections among the mathematics in a variety of problems or a variety of solutions to the same problem.

MPSKT should also include the nature of PS. For example, teachers should understand PS not only as a process but also as a way of thinking to teach for PS proficiency. Mayer and Wittrock (2006) described PS thinking in terms of reasoning (induction and deduction), critical thinking, creative thinking, and decision making. Mason, Burton, and Stacey (1982) relate PS thinking to mathematical thinking that involves specializing, conjecturing, generalizing, and convincing (inductive and deductive learning). These perspectives of PS are central to understanding the thinking underlying PS models or general heuristics. While Polya's (1957) PS model tends to be commonly used or referred to in mathematics education, other versions can add depth to teachers' knowledge of models of PS. Table 4 summarizes examples of these models.

While it makes sense that teachers should hold knowledge of heuristics and strategies, the literature suggests that teaching heuristics and strategies had not made significant impact on students' PS or proven to be successful (e.g. Schoenfeld, 1985, 1992; Silver, 1985). There was little evidence to suggest that teaching the use of heuristics has effectively enhanced PS performance in the classroom. More recently, Lester and Kehle (2003) also concluded, "Teaching students about problem-solving strategies and heuristics and phases of problem solving ... does little to improve students' ability to solve general mathematics problems" (p. 508). However, as Schoenfeld emphasized, knowledge of heuristic strategies 
Table 4 Models of PS

\begin{tabular}{|c|c|c|c|c|c|}
\hline $\begin{array}{l}\text { Parker (1920, p. } \\
258)\end{array}$ & $\begin{array}{l}\text { Kepler (1571- } \\
\text { 1630) (in Parker } \\
\text { 1920, p. 258) }\end{array}$ & $\begin{array}{l}\text { Polya } \\
(1957)\end{array}$ & $\begin{array}{l}\text { Schoenfeld } \\
\text { (1985) }\end{array}$ & $\begin{array}{l}\text { Mason, Burton, \& } \\
\text { Stacey (1982) }\end{array}$ & $\begin{array}{l}\text { Mayer \& Wittrock } \\
(2006)\end{array}$ \\
\hline $\begin{array}{l}\text { Origin in some } \\
\text { perplexity } \\
\text { Form a tentative } \\
\text { plan based on } \\
\text { analogous past } \\
\text { experience and } \\
\text { prior knowledge } \\
\text { Plan not accepted } \\
\text { until carefully } \\
\text { examined and } \\
\text { criticized }\end{array}$ & $\begin{array}{l}\text { Prolonged careful } \\
\text { search for } \\
\text { suggested } \\
\text { solutions } \\
\text { Careful open- } \\
\text { minded } \\
\text { evaluation and } \\
\text { testing of each } \\
\text { suggestion or } \\
\text { plan } \\
\text { Suspended } \\
\text { judgment, } \\
\text { patience to wait } \\
\text { until the true } \\
\text { solution has been } \\
\text { discovered and } \\
\text { verified }\end{array}$ & $\begin{array}{l}\text { Understand the } \\
\text { problem } \\
\text { Devise a plan } \\
\text { Carry out the } \\
\text { plan } \\
\text { Look back }\end{array}$ & $\begin{array}{l}\text { Analysis } \\
\text { Design } \\
\text { Exploration } \\
\text { Implementation } \\
\text { Verification }\end{array}$ & $\begin{array}{l}\text { Entry } \\
\text { Attack } \\
\text { Review }\end{array}$ & $\begin{array}{l}\text { Representing } \\
\text { Planning/ } \\
\text { monitoring } \\
\text { Executing } \\
\text { Self-regulating }\end{array}$ \\
\hline
\end{tabular}

alone does not necessarily lead to PS success or PS proficiency. As indicated in table 1, heuristics form only one component of PS proficiency so the use of heuristics by itself is unlikely to be sufficient to teach PS effectively. But in terms of MPSKT, teachers should have conceptual and procedural knowledge of mathematical PS models in order to understand the stages problem solvers pass through and the thinking involved in the process of reaching a solution.

\section{$5 \quad$ Knowledge of problem posing}

MPSKT should include knowledge of problem posing in relation to PS. Problem posing, as the generation of new problems and the reformulation of given problems, is an important companion to PS, which can have a positive impact on students' mathematical thinking and enhance students' PS ability, promote diverse and flexible thinking, and improve students' attitudes and confidence in PS (English, 1997; Kilpatrick, 1987; Silver, 1994).

Problem posing could occur prior to PS when problems were being generated from a particular situation, after solving a problem when experiences from the PS context are modified or applied to new situations, or during PS when the problem solver intentionally changes his or her goals while in the process of solving the problem (Silver, 1995). Teachers need to understand problem posing in this context in order to support students in their generation of diverse and meaningful problems to develop their PS proficiency. Silver, Downs, and Leung (1996) found that in generating extensions to a given mathematics problem, both practicing and prospective teachers generated problems that were predictable, undemanding, ill-formulated, and unsolvable. Similarly, Chapman (2012) found that elementary prospective teachers found it difficult to pose problems that were open-ended. 
Some of the problems they posed were ill-formed, not mathematical, or lacking sufficient information, but not done intentionally or with awareness of these features. Other problems involved multiple operations (but not open) and potentially yes/no/don't-know answers. For some problems, open-endedness involved any interpretation or solution whether or not appropriate for the given conditions (Chapman, 2012, p. 141).

While these issues are related to knowledge of problems, they also point to knowledge teachers may not have but should have to support problem posing connected to PS proficiency.

\section{Knowledge of students as problem solvers}

MPSKT should include knowledge of students as problem solvers in order to help them to develop appropriate PS skills. Early studies focused on learners as the main cause for teaching PS being "one of the hardest and most discouraging tasks of the teacher" (Washburne \& Osborne, 1926, p. 222) and "one of the greatest challenges to elementaryschool teachers" (Johnson, 1944a, p. 396). Thus they suggested that knowledge of students' difficulties was important to teaching PS. Collectively, these studies identified a wide range of these difficulties that hindered students' success with solving word problems at the elementary school level. This included difficulties with language literacy, mathematics concepts and relationships, and PS method. Following list summarizes examples of these difficulties based on Johnson's (1944a, 1944b) review of the literature on PS from 1922 to 1944:

- Inability to read

- Inadequate understanding of vocabulary used in problems

- Carelessness in reading, resulting in the omission of essential ideas, or misreading

- Failure to comprehend the problem in whole or in part, due to inferior reading ability, inability to visualize the situation, lack of practice in solving problems, and similar conditions

- Ignorance of quantitative relations due to the lack of vocabulary or of understanding of principles

- Lack of a method for attacking problems

- Confusion of process, resulting in the random trial of any process that may come to mind

- Lack of ability in fundamentals

- Lack of knowledge of essential facts, rules, and formulas

- Ignorance of principles, rules, or processes underlying the correct solution of problems

- Insufficient mastery of computational skills

- Inability to perform the computations involved, either through forgetting of the procedure or failure to learn it

- Lack of interest due to repeated failure, difficulty and unattractiveness of problem material 
While many of these difficulties are still relevant today and knowledge of them could be helpful for teachers to be proactive in addressing them through targeted instruction, this is unlikely to support teaching for PS proficiency. What is important is for teachers to understand the nature of such difficulties conceptually and be able to interpret them from the students' perspective in order to make sense of their needs to support their PS thinking.

Later studies also suggested the need for teachers to know characteristics of good or successful problem solvers regarding the heuristics students used and their disposition in solving problems, i.e., cognitive and affective qualities. Based on Silver and Thompson's (1984, pp. 535-536) review of the literature from late 1960 s to early 1980 s, characteristics of good problem-solvers are

- Ability to grasp the structure of the problem

- Apprehend the important structural features of the problem

- Ability to visualize and interpret quantitative or spatial facts and relationships

- Generalized memory for mathematical relationships, schemes of arguments and proofs, structural characteristics, and so forth

- Ability to understand mathematical concepts and terms, to note likenesses, differences, and analogies, to identify critical elements and select correct procedures, to note irrelevant information, and to estimate and analyze

- Tend to evaluate and select from alternative solution paths, use estimation and approximation strategies, and check for the reasonableness of their solutions

- Have well- developed skills for representing mathematics problems and that they tend to perform qualitative analyses of problems before doing any computation

- Ability to exhibit flexibility of mental processes

- Ability to generalize on the basis of few examples

- Tendency to strive for clarity, simplicity, economy, and rationality of solutions

- Analyze the information in the problem more quickly, accurately, and with greater confidence than unsuccessful problem solvers

- Tend to spend more time in attempting to solve unfamiliar problems

These characteristics can help teachers to make sense of the type of PS behaviors that could support students' development of PS proficiency.

While the lists based on the review of literature provide a view of students' as problem solvers based on their difficulties and strengths, respectively, other studies have addressed students' thinking in terms of what they are able to do. For example, Romberg and Collis (1985) found that children who "differed in cognitive-processing capacity also differ in the strategies they use to solve the same verbal problems and differ in their success in finding correct answers" (p. 380). Carpenter, Ansell, Franke, Fennema, and Weisbeck (1993) found that, by the end of kindergarten, children in their study could solve a variety of problems by modeling the action or relations described in the problems. They concluded that children as young as kindergarten can invent direct model strategies to solve a variety of problems if they are given the opportunity to do so. Verschaffel, Greer, and de Corte (2000) found that without appropriate learning experiences, children tend to suspend sense-making 
regarding the reality embodied in a word problem, i.e., ignore plausibly relevant and familiar aspects of reality in answering word problems.

Teachers' knowledge of students' thinking have been shown to be useful in understanding and supporting students' PS. For example, Carpenter, Moser, and Bebout (1988) found that teachers' knowledge of children's thinking made a positive difference to their teaching of PS. Thus, recent studies have shifted to helping teachers develop knowledge of students' mathematical reasoning during PS, for example, through observation of videos and/or direct observations of students working on problems (e.g. Francisco \& Maher, 2011; Kazemi \& Franke, 2004; Maher, Landis \& Palius, 2010). Maher et al. found that studying videos about children's reasoning produced changes in a positive direction in prospective and practicing teachers' ability to identify forms of reasoning in children's PS.

In general, then, MPSKT should include knowledge of students' PS difficulties, characteristics for successful PS, and PS thinking. However, to support students' development of PS proficiency, current perspectives of learning suggest that this knowledge be understood from the perspective of the student with a focus on making sense on how to build on what students know and can do in trying to solve genuine problems on their own.

\section{$7 \quad$ Knowledge of problem-solving instruction}

MPSKT should also obviously include knowledge of instructional strategies to support PS proficiency. Early studies suggested direct instructional techniques based on what was known about students' difficulties with PS as a means to improve students' PS (e.g. Johnson, 1944; Webb \& Sherrill, 1974). But findings such as Burns and Lash (1988) are reflective of the instructional practice teachers engaged in, i.e., "showing students how to do problems and allowing them to practice similar ones were the accepted teaching techniques for ... problem solving. ... Concerns about how to teach problem solving were not a major part of the teachers' planning" (p. 378). Early studies showed that such approaches did not remedy students' difficulties (Johnson, 1944) or enhance PS (Earp, 1967; Kilpatrick, 1985).

Current reform perspectives of teaching mathematics and recent studies on PS influenced by it suggest instructional strategies that are more likely to support PS proficiency. These studies suggest the importance of teachers' role in constructivistoriented PS instruction in which students' collaboration and ways of constructing meaning were valued and encouraged (e.g. Chapman, 1999), use of technology to facilitate students' mathematical PS (Lee, 2005); children constructing their own procedures for solving problems (Carpenter, Fennema, Franke, Levi, \& Empson, 1999); pedagogical skills in navigating PS and listening to the students (Leiken, 2003); and students "taking charge" by proposing problems to their classmates and the class as a whole had to decide whether or not to work on a particular problem (Davis, 1987).

In general, teachers need to understand instructional practices for strategies and metacognition. They must have strategic competence in order to face the challenges of 
mathematical PS during instruction. They must perceive the implications of students' different approaches, whether they may be fruitful and, if not, what might make them so. They must decide when and how to intervene - when to give help and how to give assistance that supports students' success while ensuring that they retain ownership of their solution strategies; what to do when students are stuck or are pursuing a non-productive approach or spending a lot of time with it; and what to look for. Teachers will sometimes be in the position of not knowing the solution, thus needing to know how to work well without knowing all. MPSKT should also include reform-oriented approaches to assess students' PS learning and performances in the mathematics classroom (e.g. Charles, Lester, \& O'Daffer, 1987; Lesh \& Lamon, 1993; Romberg, 1995) and an understanding of the meaning of PS in the curriculum in relation to PS proficiency.

\section{$8 \quad$ Affective Factors and beliefs}

MPSKT should include knowledge of affective factors and related beliefs that could impact students' PS. As Silver and Thompson (1984) pointed out, "There is general agreement that affective factors, such as motivation, interest, self-confidence, anxiety, and perseverance, should play an important role in problem solving” (p. 537). Charles and Lester (1982) also highlighted affective factors impacting PS consisting of stress, pressure, tolerance for ambiguity, interest, motivation, anxiety to perform, perseverance, resistance to premature closure. Knowledge of such factors could help teachers to portray and support appropriate factors in the classroom. For example, Polya (1965) stressed the importance of favorable teacher attitudes in helping students in PS. Whitaker's (1978) study suggested that "teachers should continue efforts to foster favorable student reactions and sentiments toward the many facets of mathematical problem solving" (p.223).

Beliefs, as a cognitive and affective construct, are important to learning and teaching PS (Buchanan, 1987; Callejo \& Vila, 2009; Chapman, 1999; Goldin, 2009; Mayer \& Wittrock, 2006; Schoenfeld, 1992; Thompson, 1985). As Goldin (1998) concluded, "Student belief systems were identified as important, powerful facilitators of problem-solving success, or else as obstacles to it.” (p. 138). For example, Silver (1985) found that students held beliefs that mathematical problems could always be solved by using basic operations and in a few minutes; there was only one correct way to solve a problem, there was always a rule that could be followed. Based on their study, Kloosterman and Stage (1992) concluded,

Students need to believe they can do time-consuming problems, they need to see the limits of step-by-step procedures in mathematics, they need to see that time spent understanding concepts is time well spent, they need to see that word problems are an important part of mathematics, and they need to believe that effort will make them better at doing mathematics. Teachers need to help students develop these beliefs. (p. 113).

Thus, teachers' need knowledge of students' beliefs to help them to understand and develop appropriate beliefs to support PS proficiency. 
Studies also show a relationship between teachers' beliefs and teaching of PS (Andrews \& Xenofontos, 2014; Cooney, 1985; Leikin, 2003; Thompson, 1985). Thus, teachers' also need to have knowledge of their own beliefs and the impact they can have on their own and students' ability to be successful at PS. For example, beliefs such as the following held by teachers are unproductive: PS in mathematics is primarily an application of computational skills and success and failure in PS to differences in students' ability effort (Ford, 1994).

\section{Summary and conclusion}

Teachers need to hold knowledge of mathematical PS for themselves as problem solvers and to help students to become better problem solvers. Thus, teachers' knowledge of and for teaching for PS proficiency must be broader than their general ability in PS, that is, it requires more than how to solve mathematical problems. This article highlighted some key components of the MPSKT a mathematics teacher should hold, which are summarized in table 5 .

Table 5 Components of MPSKT

\begin{tabular}{ll}
\hline Knowledge of: & Description \\
$\begin{array}{l}\text { Mathematical PS } \\
\text { proficiency }\end{array}$ & Understanding what is needed for successful mathematical PS \\
Mathematical problems & $\begin{array}{l}\text { Understanding of the nature of meaningful problems; structure } \\
\text { and purpose of different types of problems; impact of problem } \\
\text { characteristics on learners }\end{array}$ \\
& Being proficient in PS \\
Mathematical PS & $\begin{array}{l}\text { Understanding of mathematical PS as a way of thinking; PS } \\
\text { models and the meaning and use of heuristics; how to }\end{array}$ \\
& $\begin{array}{l}\text { interpreting students' unusual solutions; and implications of } \\
\text { students' different approaches }\end{array}$ \\
& $\begin{array}{l}\text { Understanding of problem posing before, during and after PS } \\
\text { Problem posing }\end{array}$ \\
Students as mathematical & $\begin{array}{l}\text { Understanding what a student knows, can do, and is disposed } \\
\text { to do (e.g., students' difficulties with PS; characteristics of good } \\
\text { problem solvers }\end{array}$ \\
problem solvers; students' PS thinking)
\end{tabular}


These components of MPSKT could be classified as:

- $\quad$ PS content knowledge [PSCK] = knowledge of problems, PS, and problem posing

- Pedagogical PS knowledge [PPSK] = knowledge of students as problem solvers, instructional practices for PS

- Affective factors and beliefs

However, as noted earlier, this category-based perspective does not provide a complete picture of MPSKT. While it highlights key aspects of this knowledge, it is not the knowledge of itself, but knowing how to use it effectively that is important. Thus ways of knowing that are important for this knowledge to be held by the teacher in meaningful and usable ways for the classroom are also central in supporting PS proficiency in his or her teaching. There is also the interrelationship among the categories (Figure 1) and within each category.

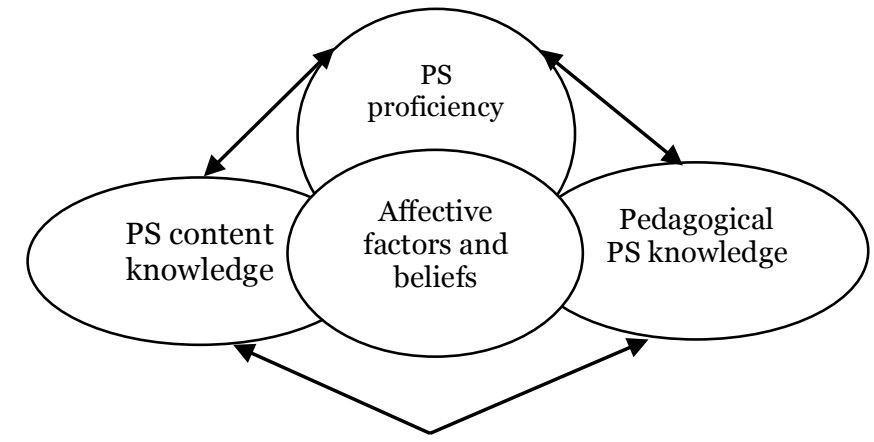

Figure 1 Interrelationships of MPSKT

It is not only knowledge of each of the categories in isolation but the connections among them that also contribute to MPSKT. MPSKT then is a complex network of interdependent knowledge. Understanding this interdependence is important to help teachers to hold MPSKT so that it is usable in a meaningful and effective way in supporting PS proficiency in their teaching. Future work is needed to understand this knowledge from the perspective of the classroom to provide a practice-based orientation of this knowledge and how to engage teachers in learning it. The perspective of MPSKT presented in this article can be built on to provide a framework of key knowledge mathematics teachers ought to hold to inform practice-based investigation of it and the design and investigation of learning experiences to help teachers to understand and develop the mathematics knowledge they need to teach for PS proficiency.

\section{References}

Andrews, P., \& Xenofontos, C. (2014). Analysing the relationship between the problem-solvingrelated beliefs, competence and teaching of three Cypriot primary teachers. Journal of Mathematics Teacher Education, (online first), DOI 10.1007/s10857-014-9287-2

Arbaugh, F., \& Brown, C. A. (2004). What makes a mathematical task worthwhile? Designing a learning tool for high school mathematics teachers. In R. R. Rubenstein \& G. W. Bright (Eds.), Perspectives on the teaching of mathematics (pp. 27-41). Reston, VA: National Council of Teachers of Mathematics. 
Ball, D. L., Thames, M. H., \& Phelps, G. (2008). Content knowledge for teaching: What makes it special? Journal of Teacher Education, 59(5), 389-408.

Buchanan, N. K. (1987). Factors contributing to mathematical problem-solving performance: an exploratory study. Educational Studies in Mathematics, 18, 399-415.

Burns, R. B., \& Lash, A. A. (March 1988). Nine seventh-grade teachers' knowledge and planning of problem-solving instruction. The Elementary School Journal, 88(4), 369-386.

Caldwell, J. H., \& Goldin, G. A. (1987). Variables affecting word problem difficulty in secondary school mathematics. Journal for Research in mathematics education, 18, 187-196.

Callejo, M. L., \& Vila, A. (2009). Approach to mathematical problem solving and students' belief systems: two case studies. Educational Studies in Mathematics, 72(1), 111-126.

Carpenter, T., Fennema, E., Peterson, P. L., \& Carey, D. (1988). Teachers' pedagogical content knowledge of students' problem solving in elementary arithmetic. Journal for Research in Mathematics Education, 19, 385-401.

Carpenter, T. P., Moser, J. M., \& Bebout, H. C. (1988). Representation of addition and subtraction word problems. Journal for Research in Mathematics Education, 19, 345-357

Carpenter, T. P., Ansell, E., Franke, M. L., Fennema, E., \& Weisbeck, L. (1993). Models of Problem Solving: A Study of Kindergarten Children's Problem-Solving Processes. Journal for Research in Mathematics Education, 24(5), 427-440.

Carpenter, T. P., Fennema, E., Franke, M. L., Levi, L., \& Empson, S. B. (1999). Children's mathematics: Cognitively Guided Instruction. Portsmouth, NH: Heinemann.

Chapman, O. (1999). Inservice teacher development in mathematical problem solving. Journal of Mathematics Teacher Education, 2, 121-142.

Chapman, O. (2005). Constructing pedagogical knowledge of problems solving: preservice mathematics teachers. In H.L. Chick \& J.L. Vincent (Eds.), Proceedings of the 29th Meeting of the International Group for the Psychology of Mathematics Education (vol. 2, pp. 225-232). Melbourne, AU.

Chapman, O. (2009a). Teachers' conceptions and use of mathematical contextual problems. In L. Verschaffel, B. Greer, W. Van Dooren, \& S. Mukhopadhyay (Eds.) Words and worlds: Modelling verbal descriptions of situations (pp. 227-244). Rotterdam: Sense Publishers

Chapman, O. (2009b). Self-study as a basis of prospective mathematics teachers' learning of problem solving for teaching. In S. Lerman \& B. Davis (Eds.), Mathematical actions and structures of noticing (pp. 163-174). Rotterdam: Sense Publishers.

Chapman, O. (2012). Prospective elementary school teachers' ways of making sense of mathematical problem posing, PNA, 6(4), 135 - 146.

Charles, R., \& Lester, F. (1982). Teaching problem solving: What, why and how. Palo Alto, CA: Dale Seymour Publications.

Charles, R., Lester, F., \& O’Daffer, P. (1987). How to evaluate progress in problem solving. Reston, VA: National Council of Teachers of Mathematics.

Cooney, T. J. (1985). A beginning teacher's view of problem solving. Journal for Research in Mathematics Education, 16(5), 324-336.

Crespo, S., \& Sinclair, N. (2008). What makes a problem mathematically interesting? Inviting prospective teachers to pose better problems. Journal of Mathematics Teacher Education, 11(5), 395-415.

Davis, R. (1987). "Taking charge” as an ingredient in effective problem solving in mathematics. Journal of Mathematical Behavior, 6(3), 341-351.

De Corte, E., \& Verschaffel, L. (1987). The effect of semantic structure on first graders' strategies for solving addition and subtraction word problems. Journal for Research in Mathematics Education, 18, 363-381.

Earp, W. N. (1967). Problem solving - Arithmetic's persistent dilemma. School Science and Mathematics, 67, 182-188. 
English, L. (1997). The development of fifth-grade children's problem-posing abilities. Educational Studies in Mathematics, 34, 183-217.

Ford, M. I. (1994). Teachers' beliefs about mathematical problem solving in the elementary school. School Science and Mathematics, 94(6), 314-322.

Francisco, N. P., \& Maher, C. (2011). Teachers attending to students' mathematical reasoning: lessons from an after-school research program. Journal of Mathematics Teacher Education, 14, 49-66.

Goldin, G. A. (1998). Representational systems, learning, and problem solving in mathematics. Journal of Mathematical Behavior, 17(2), 137-165.

Goldin, G. A. (2009). The affective domain and students' mathematical inventiveness. In R. Leikin, A. Berman, \& B. Koichu (Eds.), Creativity in mathematics and the education of gifted students (pp. 181-194). Rotterdam: Sense Publishers.

Guberman, R., \& Leikin, R. (2013). Interesting and difficult mathematical problems: changing teachers' views by employing multiple-solution tasks. Journal of Mathematics Teacher Education, 16, 33-56.

Johnson, H. C. (1944a). Problem-Solving in Arithmetic: A Review of the Literature I. The Elementary School Journal, 44(7), 396-403.

Johnson, H. C. (1944b). Problem-Solving in Arithmetic: A Review of the Literature II. The Elementary School Journal, 44(8), 476-482.

Kazemi, E., \& Franke, M. L. (2004). Teacher learning in mathematics: Using student work to promote collective inquiry. Journal of Mathematics Teacher Education, 7, 203-235.

Kilpatrick, J. (1985). A retrospective account of the past twenty-five years of research on teaching mathematical problem solving. In E. A. Silver (Ed.), Teaching and learning mathematical problem solving: Multiple research perspectives (pp. 1-15). Hillsdale, NJ: Erlbaum.

Kilpatrick, J. (1987). Problem formulating: where do good problems come from? In A.H. Schoenfeld (Ed.), Cognitive Science and Mathematics Education (pp. 123-147). Hillsdale: Lawrence Erlbaum.

Kilpatrick, J., Swafford, J., \& Findell, B. (Eds.). (2001). Adding it up: Helping children learn mathematics. Washington, DC: National Academy Press.

Kloosterman, P. \& Frances K. Stage, F. K. (1992). Measuring beliefs about mathematical problem solving. School Science and Mathematics, 92(3), 109-115

Lee, H. S. (2005). Facilitating students' problem solving in a technological context: prospective teachers' learning trajectory. Journal of Mathematics Teacher Education, 8, 223-254.

Lee, J-E. (2012). Prospective elementary teachers' perceptions of real-life connections reflected in posing and evaluating story problems. Journal of Mathematics Teacher Education, 15(6), 420452.

Leikin, R. (2003). Problem-solving preferences of mathematics teachers: focusing on symmetry. Journal of Mathematics Teacher Education, 6(4), 297-329.

Lesh, R., \& Lamon, S. J. (Eds.) (1993). Assessment of authentic performance in school mathematics. Washington, DC: AAAS.

Lester, F. K., \& Kehle, P. E. (2003). From problem solving to modeling: The evolution of thinking about research on complex mathematical activity. In R. A. Lesh \& H.M. doer (eds.), Beyond constructivism: Models and modeling perspectives on mathematics problem solving, learning and teaching (pp. 501-518). Mahwah, NJ: Erlbaum.

Levenson, E. (2013). Tasks that may occasion mathematical creativity: Teachers' choices. Journal of Mathematics Teacher Education, 16(4), 269-291.

Lewis, A. B., \& Mayer, R. E. (1987). Students' miscomprehension of relational statements in arithmetic word problems. Journal of Educational Psychology, 79, 363-371.

Maher, C. A., Landis, J. H., \& Palius, M. F. (2010). Teachers attending to students' reasoning: Using videos as tools. Journal of Mathematics Education, 3(2), 1-24.

Mason, J., Burton, L., \& Stacey, K. (1982). Thinking mathematically. New York: Addison-Wesley. 
Mason, J., Burton, L., \& Stacey, K. (2010). Thinking mathematically (2nd edition). New York: Prentice Hall.

Mayer, R. E., \& Wittrock, R. C. (2006). Problem solving. In P. A. Alexander \& P. H. Winne (Eds.), Handbook of educational psychology (2nd ed.), (pp. 287-304). Mahwah, NJ: Erlbaum.

Moyer, J. C., Moyer, M. B., Sowder, L., \& Threadgill-Sowder, J. (1984). Story problem formats: Verbal versus telegraphic. Journal for Research in mathematics Education, 15(1), 64-68

National Council of Teachers of Mathematics (2000). Principals and Standards for School Mathematics. Reston, VA: NCTM.

Norton, A., \& Kastberg, S. (2012). Learning to pose cognitively demanding tasks through letter writing. Journal of Mathematics Teacher Education, 15(2), 109-130.

Parker, S. C. (1920). Problem-Solving or Practice in Thinking IV. The Elementary School Journal, 21(4), 257-272

Polya, G. (1957). How to solve it (2nd edition). New York, NY: Doubleday.

Polya, G. (1962). Mathematical discovery: On understanding, learning, and teaching problem solving (vol.1). New York, NY: John Wiley \& Sons.

Polya, G. (1965). Mathematical discovery: On understanding, learning, and teaching problem solving (vol. 2). New York, NY: John Wiley \& Sons.

Romberg, T. A. (Ed.) (1995). Reform in school mathematics and authentic assessment. Albany, NY: SUNY Press.

Romberg, T. A., \& Collis, K. F. (1985). Cognitive functioning and performance on addition and subtraction word problems. Journal for Research in Mathematics Education, 16(5), 375-382.

Rowland, T., \& Ruthven, K. (Eds.). (2011). Mathematical knowledge in teaching. New York, NY: Springer.

Schoenfeld, A. H. (1985). Mathematical problem solving. London: Academic Press.

Schoenfeld, A. H. (1992). Learning to think mathematically: Problem solving, metacognition and sense making in mathematics. In D. A. Grouws (Ed.), Handbook of research on mathematics teaching and learning (pp. 334-370). New York, NY: Macmillan.

Silver, E. A. (1985). Research on teaching mathematical problem solving: Some underrepresented themes and needed directions. In E. A. Silver (Ed.), Teaching and learning mathematical problem solving: Multiple research perspectives (pp. 247-266). Hillsdale, NJ: Erlbaum.

Silver, E. A. (1994). On mathematical problem solving. For the Learning of Mathematics, 14(1), 1928.

Silver, E. A. (1995). The nature and use of open problems in mathematics education: Mathematical and pedagogical perspectives. International Reviews on Mathematical Education, 27, 67-72.

Silver, E. A., Mamona-Downs, J., \& Leung, S. S. (1996). Posing mathematical problems: An exploratory study. Journal for Research in Mathematics Education, 27, 293-309.

Silver, E. A., \& Thompson, A. G. (1984). Research Perspectives on Problem Solving in Elementary School Mathematics. The Elementary School Journal, 84(5), 529-545.

Slavit, D., \& Nelson, T. H. (2010). Collaborative teacher inquiry as a tool for building theory on the development and use of rich mathematical tasks. Journal of Mathematics Teacher Education, 13(3), 201-221.

Szydlik, J. E., Szydlik, S. D., \& Benson, S. R. (2003). Exploring changes in preservice elementary teachers' mathematics beliefs. Journal of Mathematics Teacher Education, 6(3), 253-279.

Taplin, M. (1994). Development of a model to enhance managerial strategies in problem solving. Mathematics Education Research Journal, 6(1), 79-93.

Taplin, M. (1998). Preservice Teachers' Problem-Solving Processes. Mathematics Education Research Journal, 10(3), 59-76.

Thompson, A. G. (1985). Teachers' conceptions of mathematics and the teaching of problem solving. In E. A. Silver (Ed.), Teaching and learning mathematical problem solving: Multiple research perspectives (pp. 281-294). Hillsdale, NJ: Erlbaum. 
Tirosh, D., \& Graeber, A. (1989). Preservice elementary teachers' explicit beliefs about multiplication and division. Educational Studies in Mathematics, 20, 79-96.

Tirosh, D., Tirosh, C., Graeber, A., \& Wilson, J. (1991). Computer-based intervention to correct preservice teachers' misconceptions about the operation of division. Journal of Computers in Mathematics and Science Teaching, 10, 71-78.

Van Dooren, W., Verschaffel, L., \& Onghena, P. (2003). Preservice teachers' preferred strategies for solving Arithmetic and Algebra word problems. Journal of Mathematics Teacher Education, 6(1), 27-52.

Verschaffel, L., Greer, B., \& De Corte, E. (2000). Making sense of word problems. Lisse: Swets \& Zeitlinger B. V.

Washburne, C. W., \& Osborne, R. (1926). Solving arithmetic problems. I. The Elementary School Journal, 27(3), 219-226.

Webb, L. F., \& Sherrill, J. M. (1974) The effects of differing presentations of mathematical word problems upon the achievement of preservice elementary teachers. School Science and Mathematics, 74(7), 559-565.

Whitaker, D. R. (1978). Mathematical Problem Solving Performance as Related to Student and Teacher Attitudes. School Science and Mathematics, 78, 217- 224. 